\title{
A vs. en in Spanish Locatives ${ }^{1}$
}

\author{
Juan Romeu \\ CCHS-CSIC \\ juanromeux@hotmail.com
}

\section{Abstract}

In this paper, we analyze the internal syntactico-semantic structure of the P(reposition)s $a$ and en in Spanish locative constructions. After providing a cartographic approach to Ps, where these elements are decomposed into more projections than Path and Place (Jackendoff 1983), in line with Svenonius (2010), we claim that the difference between $a$ and $e n$ is that $a$ lexicalizes a Terminal feature in Spanish, which en is not able to lexicalize. This feature gives the interpretation that the location of the Figure ${ }^{2}$ is not the only one with which it establishes a relationship in a single locative event.

\section{Introduction}

In Spanish, although the preposition en is most common in locative constructions like in (1a), the preposition $a$ is also used in certain locative constructions, like in (1b) and (1c):

(1a) Juan está $\{$ en/*a\} la iglesia.

Juan is en/a $a^{3}$ the church

'Juan is in the church.'

$\mathbf{1}$ The research underlying this work has been partly supported by Grant FFI2009-07114 from the Spanish Ministerio de Ciencia e Innovación and by Grant JAE Predoc from the Consejo Superior de Investigaciones Científicas.

$\mathbf{2}$ In Talmy (1975), Figure is opposed to Ground. The Figure is the entity whose location is being described. The Ground corresponds to the location where the Figure is located or the location with respect to which the Figure moves. Figure and Ground correspond to Trajector and Landmark in other frameworks. In John is in Barcelona, John is the Figure and Barcelona is the Ground.

3 We leave $a$ and en in Spanish in the glosses because we don't want the reader to get confused between the meaning of these Spanish Ps and the Ps in English into which these Ps are normally translated, i.e. at and in, respectively.

\section{(cc) BY-NC-ND}


(1b) La casa está $\{a / * e n\}$ la derecha de la iglesia. The house is a/en the right of the church 'The house is on the right of the church.'

(1c) Tesalónica está \{a/en\} el norte de Grecia. Thessaloniki is a/en the north of Greece 'Thessaloniki is at/in the north of Greece.'

The most remarkable point in these examples is the use of the preposition $a$ in locative constructions. This $P$ is normally used in directional constructions in Spanish, unlike en, whose use in directional constructions is restricted to cases with entrar ('go in, enter') and other verbs of that kind:

(2a) Juan fue $\{a / *$ en\} la iglesia.

'Juan went to the church.'

(2b) Los niños llegaron \{a/*en\} casa.

'The kids arrived home.'

Another important point is that, as we have seen in (1a), the use of $a$ is more restricted than the use of en in locative constructions. As we can observe in (1), $a$ is not possible when combined with entities like church.

In this paper, we will show that a needs to combine with Grounds that correspond to parts related or connected to another location, like derecha in (1b), which needs to be interpreted as a dependent subpart of the church. As we will see, in case it is not intended to interpret this dependency, the element en is used. This gives the two possibilities in (1c).

In the next section, we will explain the most relevant properties of the cartographic model, which we are going to use to analyze these contrasts. In section 3, we will show the locative cases in which the preposition a can appear and we will explain that these cases are those in which two locations can be interpreted in a single locative event by different means. With this, we will show that a cartographic approach is the best way to explain the minimal contrasts that we are analyzing here.

\section{A Cartographic Approach to Ps}

Before analyzing the differences between $a$ and en, we will present the so-called cartographic model, which we consider to be the most adequate model to deal with very fine contrasts, as those between $a$ and en in Spanish. 


\subsection{Background}

Once it was assumed that Ps are lexical categories (Chomsky 1970, Emonds 1972, Jackendoff 1973), it became necessary to split the structure of spatial Ps into more projections to explain subtle properties of Ps. Jackendoff (1983) decomposed Ps into Path and Place. Since then, following a cartographic model (cf. Belletti 2004, Cinque 1999, 2006, Rizzi 1997, 2004, a.o.), many scholars (cf. Koopman 2000, Den Dikken 2010a, Svenonius 2006, 2010, Pantcheva 2011, a.o.) have proposed different decompositions of $P$ into more fine-grained projections, in order to explain constructions for which the Path-Place decomposition was not enough.

Here we will work in this way, arguing that the best way to understand the contrasts between $a$ and en in locative constructions is by means of a cartographic approach.

\subsection{A Cartographic Approach to Spatial Ps}

Although there have been many attempts to capture the structure that underlies spatial constructions in languages (cf. Den Dikken 2010a, 2010b, Pantcheva 2011 , a.o.), we think that they are not accurate enough to explain the contrasts we are analyzing in this paper.

From our point of view, the most adequate model in the literature is the one proposed by Svenonius $(2006,2010)$. Svenonius decomposes Place into different syntactic projections, each one corresponding to a semantic feature, in line with Pollock's (1989) "one feature, one head" claim. For Svenonius (2010), "each component of the semantic decomposition corresponds to a syntactic projection". In this sense, he establishes a whole set of functional projections that can explain complex spatial examples such as ten meters behind the house (Svenonius 2010:134).

Although we are not going to present here the whole structure proposed by Svenonius, we will provide an example of one of the projections into which he suggests Place has to be split. This projection is going to be useful for us later in this paper.

Svenonius (2006) claims that, to explain the difference between examples like the ones in (3), it is necessary to have at least one projection more than Place in the structure:

(3a) There was a kangaroo in the front of the car.

(3b) There was a kangaroo in front of the car. Svenonius (2006:49-50) 
Based on Jackendoff (1996) and Marr (1982), he claims that in cases like (3b) there must exist a projection called $A x($ ial)Part. This projection makes front behave as a special noun. Although it preserves some properties of nouns, like, as we will see, the article in Spanish, it lacks other properties of nouns like the possibility of pluralization in English: *There were kangaroos in fronts of the cars. Svenonius (2006) gives many other tests that show that AxParts are different from Ns. ${ }^{4}$

The important thing is that "AxPart [...] is a function from eigenplaces to subparts of them" (Svenonius (2010:132), where eigenplace corresponds to "the space occupied by the Ground" (Svenonius 2010:132), as in Wunderlich (1991), or, in other words, a Region. Thus, AxPart gives a location related to a Region. This new location corresponds to a subpart of the Ground, which can be internal or external (Wunderlich 1991, Svenonius 2006)5. For instance, in (3b), front represents a part related to the car, in this case the external part in front of it:

(4)

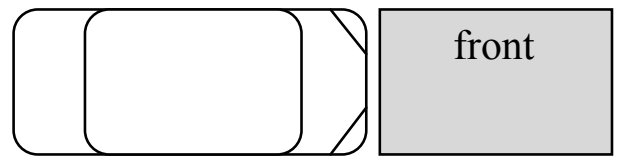

In the schema in (4), the grey square corresponds to the external front part of the car. ${ }^{6}$ This part is interpreted as connected to the location of the car and not as an independent location by means of AxPart.

Following this method, we will try to examine if the difference between $a$ and en has to do with the presence of a feature in the structure. This way, we will demonstrate that the preposition $a$ in Spanish, even in locative constructions,

\footnotetext{
4 Pluralization is possible in certain cases, as a reviewer points out:

(i) La casa está a orillas del río

the house is a riverside.pl of.the river

'The house is at the river side'

We consider such examples to be idiosyncrasies, which are possible because of the nominal origin of AxParts (Svenonius 2006:61-65). The idea is that even in cases like this one, not all the nominal properties are active. For instance, in (i) it is not possible to add an adjective.

5 For external cases, Svenonius (2010) uses the concept of 'aura', meaning that the noun refers to a part of the Ground, which corresponds to an external part of it, but belonging to it in some sense.

6 Of course, the part considered as the front will depend on the frame of reference, such as the viewer, the intrinsic properties of an object, etc. See Svenonius (2010:131) and references therein.
} 
lexicalizes ${ }^{7}$ a feature, which can be related to directionality (concretely Terminal, as we will see in next section). In contrast to Fábregas (2007) or Real Puigdollers (2010), we argue that $a$ is not just a locative P. Nevertheless, in contrast to authors like Demonte (2011), who considers $a$ to be directional, we argue that the preposition a lexicalizes also locative features. Thus, we will see in this paper that $a$ in Spanish can be considered a locative and directional $P$ at the same time because it lexicalizes features related to both location and directionality.

Following Svenonius' method, we suggest that there must be a feature in the structure above Place that explains the difference between en and $a$ in Spanish. We call this feature Terminal. The name 'Terminal' comes from Hale's (1986:239-240) opposition between central coincidence and terminal coincidence:

(5) Central coincidence: "the centre of the figure coincides with the centre of the place"

Terminal coincidence: "the location of the figure corresponds to its trajectory [...], which can be viewed as ending [...] or beginning [...] at the place"

The reason why we use 'Terminal' for this feature is because it gives the possibility to a Figure to establish a dynamic relationship with the Ground, making it possible to have a trajectory. In fact, Hale \& Keyser (2002) relate central coincidence to stativity and terminal coincidence to dynamicity. Nevertheless, as we will see later, the Terminal feature doesn't obligatorily imply dynamicity. Its presence is just the first step for dynamicity to be possible.

Then, what is the role of Terminal? We claim that it takes a location in an event and it makes it be understood as displaced with respect to other location. It gives the possibility of having two locations at stake in a single event. For this, it is necessary that at least two locations are available in the event. The Figure can then establish a locative relationship with these locations or, at least, it must be possible to have the interpretation of such a relationship.

In directional constructions, it is easy to interpret that the Figure stays in two different locations because it moves from one to the other. The main point here is to demonstrate that, even though in locative and, hence, stative cases, the Figure doesn't move from one point to the other, it is possible to interpret it

7 In this paper we take 'lexicalization' to be a post-syntactic process through which a lexical item gives phonological content to a part of the syntactic structure. This is possible by means of phrasal spell-out (see McCawley 1968, Starke 2001, Fábregas 2007, Svenonius 2010, Pantcheva 2011). 
as establishing a relationship with both. This is possible by means of Terminal. To do this, it is necessary that two locations are interpreted in a locative-stative event. In the next section, we will show how this is possible by different means. We will also show that $a$ lexicalizes Terminal and that is why, when it appears in locative constructions, it needs two locations to be somehow interpreted in the event and that the Figure is interpreted as establishing a relationship, despite its lack of movement.

\section{A vs. en}

With the Terminal feature in our minds, we are on the right track to understand the contrasts between $a$ and en that we presented before and that we repeat now:

(6a) Juan está $\{$ en/*a\} la iglesia.

Juan is en/a the church

'Juan is in the church.'

(6b) La casa está $\{a / * e n\}$ la derecha de la iglesia.

The house is a/en the right of the church

'The house is on the right of the church.'

(6c) Tesalónica está \{a/en\} el norte de Grecia.

Thessaloniki is a/en the north of Greece

'Thessaloniki is at/in the north of Greece.'

\subsection{Are These Ps Locative?}

If we apply Svenonius' (2010) tests for locatives to $a$ and en, these Ps seem to behave as locatives. For instance, Svenonius argues that locative Ps can combine with verbs such as remain, stay or be located (estar, permanecer...):

(7a) John stayed in the city.

(7b) *John stayed to the city.

(8a) Juan permaneció $\{$ en/*a\} el colegio.

Juan remained en/a the school

(8b) Juan permaneció $\{$ en/a\} el fondo de la clase.

Juan remained en/a the bottom of the classroom

(8c) *Juan permaneció hasta el colegio.

Juan remained up-to the school 
As we can see, directional Ps such as to in English or hasta in Spanish ((7b) and (8c), respectively) can't combine with the relevant verbs. We also observe that en is always possible, as in (8a) and (8b), whereas a seems to be possible only in some cases ((8b)). Taking into account this and the fact that in other Romance languages like French or Catalan the alleged equivalent of a can appear in locative cases like the one in (8a), it is essential to examine the locative cases in which $a$ is possible. This is what we will do now.

\subsection{In Which Locative Cases Can a Show Up?}

Here we present some more cases in which a is possible in a locative construction:

(9a) La casa está a la derecha de la iglesia. the house is a the right of the church

(9b) El puerto está a la orilla del mar. the harbour is a the shore of sea

(9c) Tesalónica está al norte de Grecia. Thessaloniki is a-the north of Greece

(9d) El agua está a 50 grados. the water is a 50 degrees

(9e) Juan está al piano. Juan is a-the piano

What do all these examples have in common? According to Fábregas (2007), we can classify all these cases in three groups depending on the properties of the noun $a$ combines with. First of all, there are those cases in which the noun denotes an (oriented) boundary of objects (Fábregas 2007):

(10) lado 'side', borde 'border', límite 'limit', margen 'margin', fondo 'end, bottom', término 'terminal', vera 'side of a river', entrada 'entrance', salida 'exit', frente 'front', norte 'north', derecha 'right'...

Fábregas (2007:178-179)

These cases are the ones represented in (9a) through (9c).

The second group, represented in (9d), is formed by nouns which correspond to points inside scales:

(11) máximo 'maximum', mínimo 'minimum', principio 'beginning', final 'end', mitad 'middle' (Fábregas 2007:179)

The last group ((9e)) has to do with pragmatics: 
(12) piano 'piano', teléfono 'telephone', sol 'sun', volante 'steering wheel'...

(Fábregas 2007:179-180)

As we will see later, for Fábregas (2007), all these cases have in common that "the figure is in contact with (at least) one point of the boundary of the ground". For us, as we will show later, what all these examples have in common is that the location of the Figure is not the only one at stake in the event, but it is related to other location.

So, taking an example like (9c) from the first group, we see how el norte needs to be related to the centre of Greece. Recalling what we said about AxParts, this is exactly a case where a noun is not behaving as a noun referring to a place but as a subpart of a place. So the first group of locative cases with a corresponds to cases in which the preposition doesn't combine directly with $\mathrm{N}$, but with an AxPart.

Before we said that, for Terminal to be possible, it needs two locations in the event. In AxPart cases we have, precisely, those two locations: the subpart (el norte in (9c)) and the referential Ground (Grecia in (9c)). However, it is also necessary that the two locations are connected. This is what AxPart makes possible. If the two locations are not interpreted as connected or, in other words, if el norte is not interpreted as a subpart of Grecia, but as an independent location, then el norte is not an AxPart and, thus, it is not possible to interpret two locations in the event. In that case, Terminal would not be possible, and only en is possible. This is borne out by the following example:

(13) Tesalónica está (en/*a) el maravilloso norte de Grecia.

'Thessaloniki is in the marvelous North of Greece.'

If el norte behaves as a normal $\mathrm{N}$ and not as an Axpart, then there is only one location at stake in the event (el norte de Grecia) and not two (el norte as a subpart of Grecia and Grecia as the referential location). The difference is that in the former de Grecia doesn't behave as a referential location for el norte, but just as a modifier.

This can also be demonstrated by means of a Measure Phrase. As in (9c), where $a$ is present, there are two locations, the distance between them can be "measured". On the contrary, in (13) there is no distance because it is a case of central coincidence, so the PP can't be measured:

(14a) Tesalónica está 15 kilómetros al norte.

(14b) *Tesalónica está 15 kilómetros en el norte.

'Thessaloniki is 15 kilometres towards the north.'

Fábregas (2007:178) says that these examples can be explained assuming that "locative $a$ denotes a place relationship where the figure is in contact with (at least) one point of the boundary of the ground". It is true that in the cases in which there is a contact with the boundary, $a$ is needed. But the main reason 
is that in locative cases with $a$ there are two locations at stake. This includes boundary cases, in which the two locations correspond to the boundary and the referential Ground, but also other cases in which it is not so clear that the other location corresponds to a boundary like in the following examples:

(15a) La biblioteca está a la vuelta de mi casa.

'The library is around my house.'

(15b) La iglesia está a mitad de camino.

'The church is half-way'

(15c) El vaso está más a la derecha que al centro.

'The glass is more to the right than to the centre.'

We claim that the common property of all these examples is that it is possible to interpret two locations, regardless of the stativity of the event, and, although the Figure is just located in one of them, this location is interpreted as being displaced from the referential one. This is possible by means of Terminal. Thus, although Terminal doesn't imply real dynamicity, its presence is the first step to obtain dynamicity. The interpretation of two locations is necessary in order to have movement in the event. ${ }^{8}$

The second group can be explained by assuming that a scale is like a path formed by different separated points. So in the following examples the two necessary locations for Terminal correspond to the point of the scale being chosen and an idealized neutral point of the scale:

(16a) El agua está a 100 grados.

the water is a 100 degrees

(16b) La ventana está a 7 metros.

the window is a 7 meters

In these cases, the point of the scale that is chosen is interpreted as a reached point. The scale allows the presence of Terminal, because any point belonging to a scale can be related at least to a referential point.

Finally, although we won't say much about the last group, i.e. the group that has to do with pragmatic factors, consider the following example:

(17) Juan está al volante.

Juan is a-the steering-wheel

'Juan is driving.'

8 In this sense, Brucart (2010) suggests that the preposition $a$ is 'more dynamic' than the preposition en and that in locative cases with $a$ there is an implicit path. 
As we see, here the interpretation is that Juan is driving and not that Juan is in a locative relationship with the steering wheel. A possible explanation of these cases might be that in all these cases the Figure has to approach the Ground somehow. In a case like (17), Juan has to move his arms towards the steering wheel. This dynamic action may give rise to the presence of Terminal and, thus, to the presence of $a$ in Spanish. However, these cases need a better explanation which we hope to return to in further research.

In sum, we have seen that in all the cases where $a$ appears it is necessary to interpret the Figure as being spatially related to two different locations in a single event, even in locative cases. This is possible by means of Terminal. Now, let's see how this is represented in the structure.

\subsection{The Different Structure of $a$ and en in Spanish.}

So far, we have said that, whenever a Terminal feature is present, only $a$ and not en is able to lexicalize the structure in Spanish, and, conversely, that when there is no Terminal feature present, only en and not a can lexicalize the structure. So, assuming that both $a$ and en lexicalize a Place feature, the representation of the structure is the following one (abstracting away from irrelevant structure):

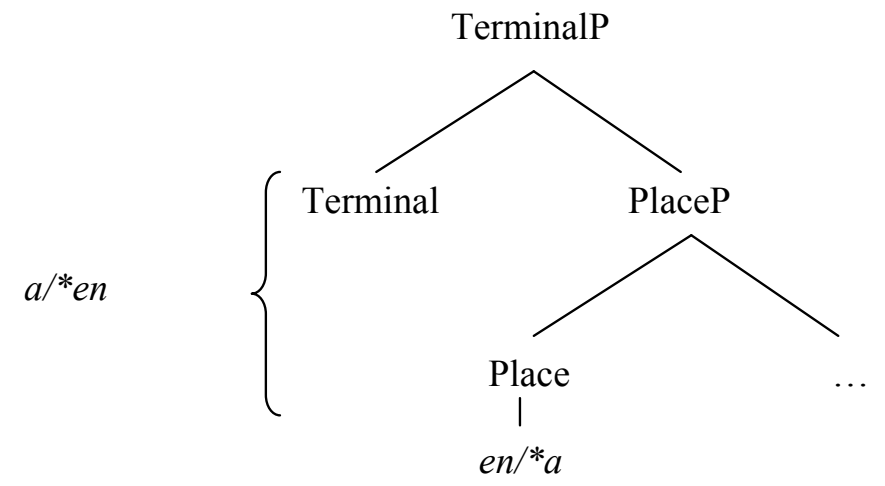

What this structure represents is that, when only Place and not Terminal is present in the structure, en is the lexical item chosen in Spanish to lexicalize it. On the contrary, when both Place and Terminal are present, $a$ is the lexical item chosen. ${ }^{9}$

9 The brace represents that a lexicalizes both Place and Terminal at the same time, by means of phrasal spell-out. This could also be explained as head movement of $a$ from Place to Terminal. 
Some remarks are needed. First of all, we can establish that the question of whether $a$ is a locative or a directional element is irrelevant. The important issue is that $a$ lexicalizes different features. As we have seen in this paper, it lexicalizes at least Place and Terminal. The fact that it lexicalizes Terminal makes a perfectly adequate for use in directional constructions, because such constructions obligatorily need a Terminal projection in their structure. At the same time, it doesn't prevent $a$ from appearing in locative constructions, as long as there are two locations at stake in the event with which the Figure is spatially related.

In this sense, we disagree with "coercing" analyses like the one in Fábregas (2007), or the one in Real Puigdollers (2010), who proposes The Extended Structural Ambiguity Hypothesis based on The Structural Ambiguity Hypothesis in Gehrke (2008). The analyses of Fábregas and Real Puigdollers are summarized in the following quotations, which correspond to Fábregas (2007:177) and Real Puigdollers (2010:129), respectively

$A$ is a locative preposition which can get a directional reading embedded under the right syntactic configuration, just like English over.

For any spatial preposition that can be interpreted as locative, it is only locative. Any ambiguity between a directional and a locative meaning is structural.

We claim that the behaviour of $a$ is not dependent on the structure in which it is embedded, i.e. by means of coercion. Rather, we claim that $a$ lexicalizes a different chunk of the structure than en. Thus, even in the locative cases, they don't lexicalize the same structure. We also suggest that it is the structure that the preposition a lexicalizes what could "coerce" the structure in which it is embedded in some cases, as can be seen in the following contrast:

(19a) Juan corrió en la iglesia (obligatorily locative)

'Juan ran in the church'

(19b) Juan corrió a la iglesia (obligatorily directional)

'Juan ran to the church'

We suggest that in (19a) the verb is just an activity verb, whereas in (19b) the verb is encoding a transition, because the presence of $a$ in the latter means that there is a Terminal feature in the structure. We intend to give a better explanation of this in the future.

Another important question has to do with the presence of Terminal in other languages. Is it possible to find examples in other languages in which Terminal triggers a different choice of a lexical item? The answer should be 'yes', and 
it seems that there are in fact such examples. In certain locative constructions in English, to is the element chosen. Interestingly, in those cases Axparts are present, as in (20):

(20a) The Palace Museum is to the north of Tiananmen Square.

(20b) My house is to the left of the elevator.

Similarly, the presence of accusative case in directional constructions in German might possibly be explained by the presence of Terminal, as in the following examples from Den Dikken (2010a:112):

(21a) er rannte in dem Laden $\rightarrow$ Locative interpretation he ran in the-dat store

(21b)er rannte in den Laden $\rightarrow$ Directional interpretation he ran in(to) the-acc store

Furthermore, a reviewer points out that, for cases like the ones we have seen in this paper the preposition an is used in German, indicating the location of the Figure at the Ground's border: am Meer ('at the seaside'), an der Grenze ('at the frontier'), am Steuer ('at the steering-wheel'), am Klavier ('at the piano'). It could be that an in German lexicalizes Terminal.

This could also be the explanation for cases like the following in North Sámi, from Svenonius (2011:6):

(22) Nieida bissánii Romssii

girl remained Tromsø.ill

'the girl remained in Tromsø.'

In this case, the presence of the illative case could be due to the fact that the verb remain in North Sámi implies that there is another location where the Figure should be instead of the location where it actually is.

Of course, this needs a deeper examination that we leave for further research.

\section{Brief Conclusions}

In this paper, we have seen that, in order to properly understand the behavior of lexical items, it is important to uncover their fine-grained internal structure. By doing so, we have shown that taking the preposition $a$ to be locative or directional is nonsensical. The key fact is that $a$ lexicalizes a Terminal feature which en is not able to lexicalize in Spanish. This Terminal feature explains the 
apparent double role of $a$ as a locative and directional preposition, giving a very simple explanation of why a can appear in certain locative constructions while at the same time it can appear in directional constructions: Terminal makes it possible to relate a Figure to two locations in a single event. This way, what at first sight were considered to be two different possible lexical items ( $a$ and en) for a single head, correspond in fact to two different structures. This conclusion would not have been possible without having taken a closer, microscopical and submorphemic look, which a cartographic approach allows.

Following a cartographic approach, we are able to understand the fine underlying structure that lexical items lexicalize and we can get rid of superficial classifications and labeling, as for example, the classification of lexical items into categories. We suggest that the best way to work with lexical items is taking into account the minimal features they lexicalize. 


\section{References}

Belletti, A. 2004. Aspects of the low IP area. In L. Rizzi (ed.), The Structure of CP and IP. Oxford: Oxford University Press, 16-51.

Chomsky, N. 1970. Remarks on Nominalization. In R. Jacobs and P. Rosenbaum (eds.), Readings in English Transformational Grammar. Waltham, MA: Ginn, 184221.

Cinque, G. 1999. Adverbs and functional heads. Oxford/New York: Oxford University Press.

Cinque, G. 2006. Restructuring and functional heads. Oxford: Oxford University press.

Demonte, V. 2011. Los eventos de movimiento en español: construcción léxicosintáctica y microparámetros preposicionales. In J. Cuartero Otal, L. García Fernández and C. Sinner (eds.), Estudios sobre perifrasis y aspecto. München: peniope, 16-42.

Den Dikken, M. 2010a. In G. Cinque and L. Rizzi (eds.), The cartography of Syntactic Structure, vol.6. Oxford: Oxford University Press, 74-126.

Den Dikken, M. 2010b. Directions from the GET-GO. On the syntax of manner-ofmotion verbs in directional constractions. Catalan Journal of Linguistics 9: 23-53.

Emonds, J. 1972. Evidence that indirect object movement is a structure preserving rule. Foundations of Language 8: 546-561.

Fábregas, A. 2007. An Exhaustive Lexicalisation Account of Directional Complements. Nordlyd: Tromsø Working Papers on Language and Linguistics 34(2): 165-199. 
Gehrke, B. 2008. Ps in Motion: On the Semantics and Syntax of P Elements and Motion Events. PhD dissertation, Utrecht University.

Hale, K. 1986. Notes on World View and Semantic Categories: Some Warlpiri Examples. In P. Muysken and H. van Riemsdijk (eds.), Features and Projections. Dordrecht: Foris, 233-254.

Hale, K. and S.J. Keyser. 2002. Prolegomenon to a theory of argument structure. Cambridge, MA: MIT Press.

Jackendoff, R. 1973. The Base Rules for Prepositional Phrases. In S.R. Anderson and P. Kiparsky (eds.), Festschrift for Morris Halle. New York: Holt, Rinehart \& Winston: 345-356.

Jackendoff, R. 1983. Semantics and cognition. Cambridge, MA: MIT Press.

Jackendoff, R. 1996. The proper treatment of measuring out, telicity, and perhaps even quantification in English. Natural Language and Linguistic Theory 14: 305354.

Koopman, H. 2000. Prepositions, postpositions, circumpositions and particles: The structure of Dutch PPs. In H. Koopman (ed.), The syntax of specifiers and heads. London: Routledge, 204-260.

Marr, D. 1982. Vision: A Computational Investigation into the Human Representation and Processing of Visual Information. New York: W.H. Freeman.

McCawley, J.D. 1968. Lexical insertion in a transformational grammar without Deep Structure. In B.J. Darden, C.-J.N. Bailey and A. Davidson (eds.), Papers from the fourth regional meeting of the Chicago Linguistic Society. Chicago: University of Chicago.

Pantcheva, M. 2011. Decomposing Path. The nanosyntax of directional expressions. PhD dissertation, Tromsø University.

Pollock, J.-Y. 1989. Verb Movement, Universal Grammar, and the Structure of IP. Linguistic Inquiry 20: 365-424.

Real Puigdollers, C. 2010. A microparametric approach on goal of motion constructions: properties of adpositional systems in Romance and Germanic. Catalan Journal of Linguistics 9: 125-150. 
Rizzi, L. 1997. The Fine Structure of the Left Periphery. In L. Haegeman (Ed.), Elements of Grammar. Handbook of Generative Syntax. Dordrecht: Kluwer, 73-137

Rizzi, L. (Ed.) 2004. The Structure of CP and IP - The Cartography of Syntactic Structures vol 3. Oxford: Oxford University Press.

Starke, M. 2001. Move Reduces to Merge: A Theory of Locality. PhD dissertation, University of Geneva.

Svenonius, P. 2006. The emergence of axial parts. In P. Svenonius and M. Pantcheva (eds.), Nordlyd, Tromsø. Working Papers in Language and Linguistics: 33.1, Special Issue on Adpositions. Tromsø: Tromsø University, 49-77.

Svenonius, P. 2010. Spatial P in English. In G. Cinque and L. Rizzi (eds.), The cartography of Syntactic Structure, vol.6. Oxford: Oxford University Press, 127160.

Svenonius, P. 2011. Directed Manner of Motion in North Sámi. Presented in the Workshop on Verbal Elasticity. Universitat Autònoma de Barcelona.

Talmy, L. 1975. Semantics and syntax of Motion. In J. Kimball (ed.), Syntax and Semantics vol. IV. New York: Academic Press, 181-238.

Wunderlich, D. 1991. How do prepositional phrases fit into compositional syntax and semantics?. Linguistics 29: 591-621. 